\title{
Progression from Pneumonia to ARDS as a Predictor for Fatal COVID-19
}

\author{
Chen-Yang Hsu ${ }^{1}$, Chao-Chih Lai ${ }^{2}$, Yen-Po Yeh ${ }^{1}$, Chang-Chuan Chan ${ }^{1}$, and Hsiu-Hsi Chen ${ }^{1}$ \\ ${ }^{1}$ National Taiwan University \\ ${ }^{2}$ Taipei City Hospital Jen-ai Branch
}

June 2, 2020

\begin{abstract}
There is a serious concern over the variation of case fatality that reflects the preparedness of the medical care system in response to the surge of pneumonia patients. The variation of fatal COVID-19 was in parallel with the heterogeneity of progression from pneumonia to ARDS, ranging from $3.4 \%$ to $63 \%$ based on data from 12 countries, accounting for $95 \%$ positive association between this key indicator and case fatality rate of COVID-19. Predicting fatal COVID-19 with the progression from pneumonia to ARDS is conducive to the preparedness of medical care facilities for the optimal management of a spectrum of COVID-19 patients.
\end{abstract}

\section{Introduction}

The pandemic of SARS-CoV-2, causing the disease COVID-19, has expanded from the epidemic center of Wuhan, China to the whole world in the first three months of 2020. ${ }^{1}$ As COVID-19 spread across the globe, we saw the disease has a wide variation in case-fatality, ranging from $10 \%$ in Italy to less than $1 \%$ in Germany, ${ }^{1}$ and societal impacts across countries worldwide. The spectrum of clinical severity is one factor to gauge the severity of this pandemic in addition to affected population and disease transmission. ${ }^{2}$ Whether COVID-19 is fatal or not is highly dependent on the odds of progression from mild disease to severe disease and adequacy of isolation wards and intensive care units to reduce its progression from pneumonia to severe acute respiratory disease syndrome (ARDS). ${ }^{3}$ By quantifying progression of the entire disease spectrum of COVID-19 from mild symptoms to death from publicly available clinical data, we provide evidence-based explanation for difference in case-fatalities among affected countries.

\section{Material and Methods}

We have developed a quantitative model, shown in Figure 1, for evaluating the disease progression of COVID19 through three main categories of severity, from mild respiratory disease (MRD) to pneumonia and then to severe pneumonia with ARDS. The key indicator accounting for the variable case-fatality rate is the progression rate from pneumonia to ARDS. To estimate these progression rates, published data from China, Japan, and Italy have been abstracted. ${ }^{3-5}$ The aggregate numbers abstracted from the publicly available data provide information on the frequencies of MRD, pneumonia, ARDS in need of intensive care, recovery, and death. Only three countries (China, Italy, and Japan) have so far provided fully available information on the progression of disease severity as shown in Figure 1. Regarding the information on China, the aggregated tabular data abstracted from the original article are listed in Table 1, including clinical characteristics of 1,099 patients from 552 hospitals covering 30 provinces in China. ${ }^{3}$ Information was available from Feb $6^{\text {th }}$ to Mar $13^{\text {th }} 2020$ for Japan, ${ }^{4}$ and Mar $3^{\text {th }}$ to $6^{\text {th }}$ for Italy. ${ }^{5}$ Information on other countries was retrieved from open data sources during the current epidemic period until Mar $17^{\text {th }} .^{1}$ 
The probability of each progression following the binomial distribution was first estimated on the basis of the frequencies on each state using the empirical data from three countries (China, Japan, and Italy). The pooled probabilities for disease progression from MRD to pneumonia, from MRD to recovery, and from ARDS to death were estimated by combining the data from three countries. These pooled estimates were further applied to imputing the key indicator for progression from pneumonia to ARDS for other eight countries with only information on total pneumonia cases and deaths from ARDS. The case-fatality rate was regressed on the estimated probability of progression from pneumonia to ARDS by using a linear regression equation model to calculate the adjusted $\mathrm{R}^{2}$.

\section{Results}

The probabilities of disease progression in China, Japan and Italy

During the outbreaks in China, $27.2 \%$ (95\% CI: 24.7-29.8\%) of infected persons with MRD recovered and the remaining $72.8 \%$ (95\% CI: 70.2-75.3\%) progressed to pneumonia. Of those with pneumonia, $37.8 \%$ (302/800, 95\% CI: 32.3-42.9\%) were treated as outpatients and the remaining $62.3 \%$ (498/800, 95\% CI: 58.0-66.3\%) required hospitalization. The recovery rate of the hospitalized patients was $95.4 \%$ (95\% CI: 94.0-96.8\%), and the remaining 4.6\% (95\% CI: 3.2-6.0\%) deteriorated to ARDS with a death rate of $40.5 \%$ (95\% CI:24.7-55.6\%) (Figure 1(a), Table 1).

The corresponding values for the transition from MRD to death of ARDS were calculated for Italy and Japan (Figure 1(b) and (c), Table 1). The pooled estimates for disease progression from these three countries were $72.7 \%$ from MRD to pneumonia and 27.3\% from MRD to recovery (Table 2). It should be noted that the combined fatality rate of ARDS (43\%) by pooling the estimates across three countries was comparable to that reported in a systematic review article based on meta-analysis (44\%). ${ }^{6}$ The remarkable difference in case fatality rates among these three countries was attributable to their difference in the probability of progression from pneumonia to ARDS, which was 6.8\% (95\% CI: 4.6-9.0\%) and 16.2\% (95\% CI: 14.8-17.5\%) for Japan and Italy, respectively (Figure 1 (b) and (c), Table 2).

The probability of progression from pneumonia to ARDS

The probability of progression from pneumonia to ARDS was the highest in France with $63 \%$, followed by $49.1 \%$ in UK, $41.9 \%$ in Netherlands, and the lowest, $3.4 \%$, in Taiwan (Table 2). These estimates were highly associated with the case fatality rates reported for each country with a statistically significant positive relationship (adjusted $\mathrm{R}^{2}=95 \%$, Figure 2).

External Validation

We have performed an external validation of the parameters of Figure 1 (a), calculated with data from China, using data from countries other than China but in the same epidemic wave as the China epidemic, such as the reported cases and deaths from South Korea up to March $20^{\text {th }}$ and the Diamond Princess up to Feb $27^{\text {th }}$, all available from open data allowing for a three-day delay for the COVID-19 death count. ${ }^{1}$ Appendix Table 1 shows the observed and predicted deaths for these two sets of empirical data. The number of expected deaths was 118 and 9.62 for South Korea and the Diamond Princess Cruise Ship, respectively, which were consistent with the observed data $\left(P=0.82\right.$ by the chi-square test, $\left.x_{(1)}^{2}=1.79\right)$.

\section{Discussion}

In response to the soaring number of COVID-19 cases reported in previous studies and reports ${ }^{1,3-5}$ and in the absence of approved anti-viral therapy and vaccination, a variety of non-pharmaceutical mitigation strategies have been implemented in most countries and regions attacked by COVID-19. With the rapid transmission and subsequent propagation of the COVID-19 pandemic, the ultimate goal of these containment strategies have shifted from transmission prevention centered on border control and contact tracing to plans aimed at the reduction of case fatality with the preservation of intensive care capacity. The quantitative model depicted in Figure 1 should assist in planning for the upcoming demand for healthcare personnel and 
facilities in order to minimize the consequences of COVID-19, particularly by reducing the progression from pneumonia to ARDS.

This quantitative disease progression model can assist in estimating the proportion of each of the three stages of the disease and the chances of recovery from each state, for the purpose of efficient allocation of medical resources. These include medical and paramedical personnel, isolation wards and ICUs in designated hospitals responsible for COVID-19 patients, and more importantly, guidance in triaging those identified as COVID-19 cases. Based on the disease progression parameters derived from the outbreak in China, more than half $(54.7 \%)$ of the COVID-19 cases can be treated as outpatients and be expected to recover. The remaining patients will require hospital-based treatment with a conservative estimate of an ICU demand of $3 \%$ of all confirmed COVID-19 cases.

The progression rate from pneumonia to ARDS, the key determinant of fatal outcome from COVID-19, varies considerably among the countries examined here with a range $>20$-fold. Serious efforts need to be made to reduce this rate, among which the optimal allocation of medical resources should play a major role. Preventing the progression of pneumonia to ARDS should be the management strategy given the highest priority, and the strategies employed by counties with low rates of progression should be carefully studied. Our quantitative disease progression model can assist in this process.

\section{References}

1. World Health Organization. Coronavirus disease (COVID-2019)situation reports. 2020. https://www.who.int/emergencies/diseases/novel-coronavirus-2019/situation-reports. (accessed at 29 May, 2020)

2. Lipsitch M, Swerdlow DL, Finelli L. Defining the epidemiology of Covid-19 - studies needed. NEJM 2020; $382: 1194-96$.

3. Guan WJ, Ni ZY, Hu Y, et al. Clinical Characteristics of Coronavirus Disease 2019 in China. NEJM 2020; 382 : 10.1056/NEJMoa2002032

4. Japan: Ministry of Health, Labor, and Welfare. About Coronavirus Disease 2019 (COVID-19) . 2020. https://www.mhlw.go.jp/stf/seisakunitsuite/bunya/newpage_00032.html (Accessed at 15 April, 2020)

5. Ministero della Salute, Italy. Nuovo Coronavirus Cosa C'é da sapere . 2020. http://www.salute.gov.it/portale/home.html (Accessed at 15 April, 2020)

6. Phua J, Badia JR, Adhikari NKJ, et al . Has Mortality from Acute Respiratory Distress Syndrome Decreased over Time? A systematic review. Am J Respir Crit Care Med 2008; 179 : 220-27.

Table 1. Aggregated data on the three main stages of COVID-19 progression, as abstracted from published data.

\begin{tabular}{|c|c|c|c|c|c|}
\hline & Total cases & $\begin{array}{l}\text { Cases } \\
\text { progressing } \\
\text { Frequency (\%) }\end{array}$ & $\begin{array}{l}\text { Cases } \\
\text { progressing } \\
\text { Frequency }(\%)\end{array}$ & $\begin{array}{l}\text { Cases } \\
\text { recovering } \\
\text { Frequency (\%) }\end{array}$ & $\begin{array}{l}\text { Cases } \\
\text { recovering } \\
\text { Frequency (\%) }\end{array}$ \\
\hline China & China & China & China & China & China \\
\hline All Patients & 1099 & 800 & $(72.8)$ & 299 & $(27.2)$ \\
\hline $\begin{array}{l}\text { Non-life- } \\
\text { threatening } \\
\text { pneumonia }\end{array}$ & 800 & 37 & $(4.6)$ & 763 & $(95.4)$ \\
\hline ARDS & 37 & 15 & $(40.5)$ & 22 & $(59.5)$ \\
\hline Japan & Japan & Japan & Japan & Japan & Japan \\
\hline All Patients & 659 & 468 & $(71.0)$ & 191 & $(29.0)$ \\
\hline
\end{tabular}




\begin{tabular}{llllll}
\hline & Total cases & $\begin{array}{l}\text { Cases } \\
\text { progressing } \\
\text { Frequency (\%) }\end{array}$ & $\begin{array}{l}\text { Cases } \\
\text { progressing } \\
\text { Frequency (\%) }\end{array}$ & $\begin{array}{l}\text { Cases } \\
\text { recovering } \\
\text { Frequency (\%) }\end{array}$ & $\begin{array}{l}\text { Cases } \\
\text { recovering } \\
\text { Frequency (\%) }\end{array}$ \\
\hline $\begin{array}{l}\text { Non-life- } \\
\text { threatening } \\
\text { pneumonia }\end{array}$ & 468 & 32 & $(6.8)$ & 436 & $(93.2)$ \\
ARDS & 56 & & & & \\
Italy & Italy & 24 & $(42.9)$ & 32 & $(57.1)$ \\
$\begin{array}{l}\text { All Patients } \\
\text { Non-life- }\end{array}$ & 3916 & Italy & Italy & Italy & Italy \\
threatening & 2856 & 2856 & $(72.9)$ & 1060 & $(27.1)$ \\
pneumonia & & 462 & $(16.2)$ & 2394 & $(83.8)$ \\
ARDS & 462 & & & & \\
\hline
\end{tabular}

Table 2. Disease progression rates of COVID-19 for countries with more than 20 fatal cases. $^{\text {a }}$

\begin{tabular}{llll}
\hline Country & Mild Respiratory Disease to Pneumonia & Mild Respiratory Disease to Recovery & Pneumon \\
\hline China & 72.8 & 27.2 & 4.6 \\
Japan & 71.0 & 29.0 & 6.8 \\
Italy & 72.9 & 27.1 & 16.2 \\
Iran & $72.7^{\mathrm{b}}$ & $27.3^{\mathrm{b}}$ & 20.7 \\
Spain & & & 38.8 \\
UK & & & 49.1 \\
Netherlands & & & 41.9 \\
France & & & 63.0 \\
US & & 20.4 \\
South Korea & & & 7.7 \\
Germany & & & 14.5 \\
Taiwan & & & 3.4 \\
\hline
\end{tabular}

${ }^{a}$ Estimated results in proportion (\%)

b Based on the results derived from China, Japan, and Italy

${ }^{c}$ Derived by using data on total cases and deaths reported by WHO, updated from Feb-4 to May-9, 2020. ${ }^{1}$

Figure Legends,

Figure 1. Disease progression model for COVID-19 from mild respiratory disease to pneumonia, ARDS and the terminal events of recovery and death

Figure 2. Association between the progression rate from pneumonia to ARDS and the case-fatality rate Appendices

Appendix Table 1. Observed and predicted numbers of COVID-19 deaths based on the reported results from China ${ }^{3, a}$

\begin{tabular}{llll}
\hline $\begin{array}{l}\text { Country/location of } \\
\text { COVID-19 outbreak }\end{array}$ & $\begin{array}{l}\text { COVID-19 confirmed } \\
\text { cases }^{\text {b }}\end{array}$ & $\begin{array}{l}\text { Expected deaths from } \\
\text { COVID-19 }\end{array}$ & $\begin{array}{l}\text { Observed deaths from } \\
\text { COVID-19 }\end{array}$ \\
\hline South Korea & 8652 & 118 & 111
\end{tabular}




\begin{tabular}{llll}
\hline $\begin{array}{l}\text { Country/location of } \\
\text { COVID-19 outbreak }\end{array}$ & $\begin{array}{l}\text { COVID-19 confirmed } \\
\text { cases }^{\text {b }}\end{array}$ & $\begin{array}{l}\text { Expected deaths from } \\
\text { COVID-19 }\end{array}$ & $\begin{array}{l}\text { Observed deaths from } \\
\text { COVID-19 }\end{array}$ \\
\hline $\begin{array}{l}\text { Diamond Princess } \\
\text { Cruise Ship }\end{array}$ & 705 & 9.62 & 6 \\
\hline
\end{tabular}

${ }^{\mathrm{a}} \chi^{2}=1.79$, on 1 degree of freedom, $p=0.82$

b Data of confirmed cases derived from WHO data was collected from Feb-4 to Feb-27, 2020 for the Diamond Princess Cruise Ship and through Mar-20 for South Korea ${ }^{1}$

${ }^{c}$ Data on fatal cases derived from WHO data was updated from Feb-4 to Mar-1, 2020 for the Diamond Princess Cruise Ship and through Mar-23 for South Korea ${ }^{1}$

\section{Hosted file}

2020-05-21 Figure 1.docx available at https://authorea.com/users/328873/articles/456013progression-from-pneumonia-to-ards-as-a-predictor-for-fatal-covid-19

\section{Hosted file}

2020-05-21 Figure 2.docx available at https://authorea.com/users/328873/articles/456013progression-from-pneumonia-to-ards-as-a-predictor-for-fatal-covid-19 